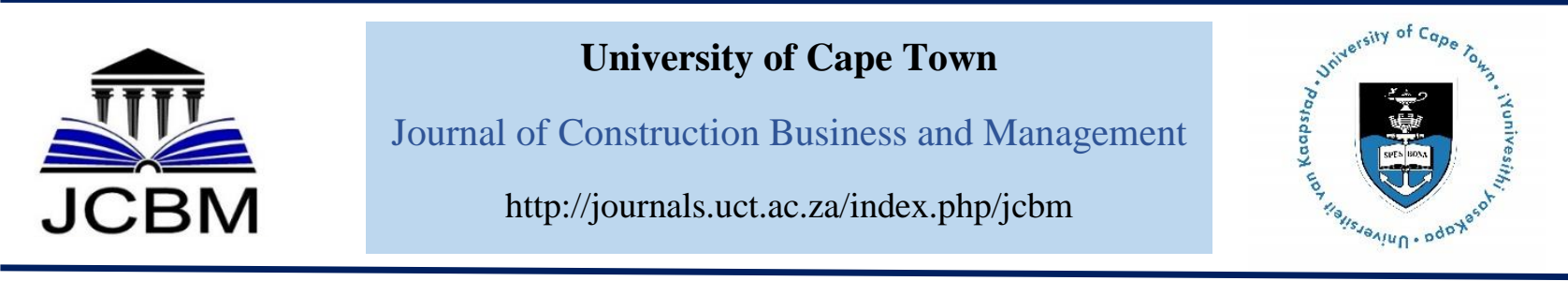

\title{
Exploring the Components of Cost on Construction Projects
}

\author{
A. Windapo ${ }^{1}$, A. Moghayedi ${ }^{2}$, D. Oliphant ${ }^{3}$ and A. Adediran ${ }^{4}$ \\ 1,2,3,4 Department of Construction Economics and Management, University of Cape Town, South Africa
}

Received 3 April 2018; received in revised form 26 June 2018, 12 July 2018; accepted 21 July 2018 https://doi.org/10.15641/jcbm.2.2.2018.573

\begin{abstract}
This study examines the components of construction projects and whether there are construction resources that are key project constituents. The rationale for the study stems from the unexplained assumptions regarding the primary components responsible for increases in construction costs in South Africa, due to the lack of a national building cost database. The study adopts a qualitative research approach that employs case studies of six new and six refurbished projects, to obtain the necessary data to answer the research questions. The study found that the primary cost constituents of construction projects were materials and sub-contracted work, accounting for $63.69 \%$ and $74.6 \%$ of the value of renovation and new construction work respectively. On the average, the major materials by value used in construction projects were identified as reinforcement, cement and filling, while electrical installation was the primary sub-contracted item by value. Based on these findings, the study concluded that future levels of construction costs could be predicted, when levels of specialist subcontractor costs and building material costs are known. To improve cost performance of project, the study recommends that the subcontractor and material inputs into construction projects should be carefully managed, both on projects and in the construction industry. The study contributes to the literature on resource planning and control in construction.
\end{abstract}

Keywords: Cement, Construction cost, Electrical installation, Reinforcement, Specialist subcontractor.

\section{Introduction}

Most construction contracts are awarded on competitive basis and this obliges tenderers to prepare bids based on accurate prediction ( $\mathrm{Ng}$, Cheung, Skitmore, Lam \& Wong, 2004). Construction clients often demand early and accurate cost advice, because this assists in determining budget, predicting tender price and managing design (Lowe, Emsley, \& Harding, 2006). However, increases in construction costs also affect the following: building contract price (Ashuri \& Lu, 2010), contractors' profit margins (in the absence of any provision in the contract) (Chappel, Cowlin, \& Dunn, 2010), and they create major financial stress and difficulties within the project lifespan. There are also effects such as the inability of developers to deliver affordable housing, high tender valuation, a decrease in tender competition and poor construction industry performance. This becomes more difficult on infrastructure projects, such as the Medupi power station in South Africa, which may experience project challenges persisting for many years.
The South African construction industry, like the other sectors of the economy, has been facing several challenges over the past few years (since 2012). With 1.431 million people employed in the construction industry (Stats SA, 2018) it plays a crucial role as a major driver of economic growth and development; thus, the need arises for a proper understanding of the main project components by value, to provide more accurate knowledge of cost indicators and inflators in the construction industry. Furthermore, due to the effect that cost increases in construction have on project performance and on construction industry stakeholders, a study is essential to identify the components responsible for the increases in the cost of construction work in South Africa. This is because so far, only unexplained assumptions have described how cost components are related to key project constituents. This paper therefore presents a review of literature on the cost of delivering infrastructure projects, and descriptions of construction cost components, in medium to large construction

\footnotetext{
${ }^{1}$ Corresponding Author. Tel: +27216502049
}

Email address: Abimbola.windapo@uct.ac.za 
projects. The research methodology used in the study is articulated, and the results of the study and the conclusions derived from the study are also presented.

\subsection{Overview of the delivery cost of construction projects}

A comparison of the construction cost per square metre between South Africa, Brazil, Russia, India and China (BRICS), the G8 and some African Union (AU) countries, shows that South Africa has relatively lower construction costs than most other countries, at only $\$ 741 /$ sq.m (Compass International Consultants Inc, 2016). Labour productivity is also lower in South Africa: it takes an average South African worker 1450 hour to complete a task, compared with 1000 hours by a labourer in the USA. The USA has the highest productivity constant globally. On the basis of the comparatively low labour cost (\$25.50/hour) and lower labour productivity in South Africa, this country continues to have lower construction costs when compared to other BRICS and AU countries (Angola, Egypt, Ghana, Kenya, Morocco and Nigeria) (Compass International Consultants Inc., 2016). Despite this advantage, construction cost in South Africa increased by $26 \%$ between 2010 and 2015 (Bureau of Economic Research, 2016). Exploring the construction components driving the increase would enable stakeholders to plan and put measures in place to address future cost increases.

\subsection{Construction cost components}

The components of construction costs consist of the resource factors (labour, materials, plant and subcontractors); project factors (profit margin, overhead costs, supervision/management, finance, transportation and exchange rates); and the cost of legislative requirements (professional fees, transaction costs and permits). Resource factors are the inputs used in the production process to produce an output - this is the final product-building or infrastructure in construction. According to Odediran and Windapo (2014), Skitmore, Runeson and Chang (2006), Lowe, Emsley, and Harding
(2006), Sawhney, Walsh and Brown IV (2004), Eastham (1986) and Snyman (2007), resource factors contributing to the cost of construction work comprise of labour, materials, equipment and subcontractors. Regarding project factors, earlier studies by Skitmore, Runeson and Chang (2006) identified overhead costs as a significant contributor to final construction cost. Olatunji (2010), Ng, Cheung, Skitmore, Lam and Wong (2000), Eastham (1986) and Snyman (2007) identified transportation costs, interest rates, fuel price and energy costs as significant contributors to construction costs. Meanwhile, previous studies by Sawhney, Walsh and Brown IV (2004), Akintoye (2000) and Eastham (1986) found that stakeholder requirements such as professional fees (for design and supervision), contract documentation/transaction costs, and legal and financial requirements were significant contributors to construction costs.

\section{Research Methodology}

A multi-case study approach was used to achieve the purpose of this study. Because the study employed a longitudinal approach, only construction cost components that were seasonal/ time based and changed consistently over time, such as labour, materials, equipment, subcontractors and project preliminaries were considered. Other cost strategies such as mark-ups/profits were not included. Only direct construction costs were considered. In this study, construction cost refers to the total value of works executed by medium to large sized general building and civil engineering contracting firm.

The details of projects and their cost estimates are presented in Table 1. The selection criteria for projects are: they were designed and planned for construction within the last five years that is 2012 to 2017 ; they were representative of public sector projects; they were of a size and tender price typical of works undertaken by mediumto -large sized general building and civil engineering contractors.

Table 1: Description of Case Studies

\begin{tabular}{|c|c|c|c|c|}
\hline No & Renovation project & $\begin{array}{l}\text { Tender Price } \\
\text { (million ZAR) }\end{array}$ & GFA $\left(\mathbf{m}^{2}\right)$ & $\begin{array}{c}\text { Tender } \\
\text { submission date }\end{array}$ \\
\hline $\mathrm{R} 1$ & Admin Building & 7,380 & $1900 \mathrm{~m}^{2}$ & 2012 \\
\hline $\mathrm{R} 2$ & School Building & 45,134 & $5336 \mathrm{~m}^{2}$ & 2016 \\
\hline R3 & Hospital & 130,304 & $2400 \mathrm{~m}^{2}$ & 2015 \\
\hline $\mathrm{R} 4$ & Road (concrete) & 98,825 (+Upgrade) & $7.98 \mathrm{Km}$ long \& $9.8 \mathrm{~m}$ wide & 2013 \\
\hline R5 & Court & Unknown & $13060 \mathrm{~m}^{2}$ & 2015 \\
\hline R6 & Community Clinic & 45 & $1950 \mathrm{~m}^{2}$ & 2016 \\
\hline No & New project & $\begin{array}{l}\text { Tender Price } \\
\text { (million ZAR) }\end{array}$ & GFA $\left(\mathrm{m}^{2}\right)$ & $\begin{array}{c}\text { Tender } \\
\text { submission date }\end{array}$ \\
\hline N1 & School Building & 10,373 & $2771 \mathrm{~m}^{2}$ & 2015 \\
\hline $\mathrm{N} 2$ & Hospital & 171,786 & $3691 \mathrm{~m}^{2}$ & 2015 \\
\hline N3 & Road (concrete) & 98,825 (+Upgrade) & $2.17 \mathrm{~km}$ long $\& 9,8 \mathrm{~m}$ wide & 2013 \\
\hline N4 & Administration Building & 56,386 & $1194 \mathrm{~m}^{2}$ & 2015 \\
\hline N5 & Municipal waste water treatment plant & 180,923 & $11300 \mathrm{~m}^{2}$ & 2015 \\
\hline N6 & Community Clinic & 45,506 & $1549 \mathrm{~m}^{2}$ & 2015 \\
\hline
\end{tabular}


The relevant priced Bills of Quantities of the 12 representative public-sector projects were obtained. Thereafter a model of the cost components for each case study was developed. This model was used to identify direct/indirect cost components: labour, materials, equipment, subcontractors and project preliminaries, and their share of the project cost envelope. The research team made use of standard estimating protocol, which included developing constants from first principles. The COMPASS Estimating Handbook (2016) was used as a reference and CCS CANDY Estimating Software (used by construction companies in South Africa) was used to develop cost models for the project.

\subsection{Specification of cost variables}

The project costs were obtained consistently for all the projects in the study, based on the following assumptions:

- Unit rates for resources were priced at industry accepted charge-out rates.

- A daily shift was specified at 8.5 working hours.

- Concrete was generally priced as mixed on-site.

- Concrete for roads would be mixed at a batch plant and pumped into position on site.

- Scaffolding requirements were priced in preliminaries.

- Carting away of discarded or surplus material was priced in preliminaries.

- Where no specification was provided, wall height was assumed to be $3 \mathrm{~m}$.

- Trades priced directly were considered to be the least specialized, namely earthworks, concrete, formwork, reinforcement, masonry, carpentry and joinery, ironmongery, plastering, tiling, plumbing, glazing, roadworks and painting.

- Inefficiencies such as delays in production were not allowed for.

- Only the cost of materials and on-site costs were considered in terms of the installation of materials; all costs required to deliver materials to the site were ignored, as these would skew the cost of the material.

- Production rates were specified as constant through the day.

- Labour costs did not include standing time.
- Building method was a constant and changes were based on the specification of the bill item.

\subsection{Main resources priced}

The main resources priced were:

- Material: cement, sand, bricks, sawn timber, fill material for earthworks and roads, diesel, reinforcement, structural steel; glazing, bitumen, tar and copper piping.

- Labour skill level: general labourer, artisan, and operator for plant.

- Plant: excavator, digger loader, road paver, and earthfilling compactor.

- Preliminaries: all indirect costs associated with construction, provided for by a lump-sum value. The factors that would cause resources to be priced in the preliminaries were that the resource would be used across all trades managed by the main contractor, and that it would be required for a long period of time on the project. Therefore, the following items were priced as preliminaries: health and safety requirements, management costs on and off-site, general scaffolding, general miscellaneous resources, commissioning requirements, head office and site overheads, costs to deliver resources to site, contractual requirements attracting a cost, and provisional sum.

- Subcontracted work: specialist installation including subcontractor overheads and management fees, delivery costs to bring resources to site and all commissioning requirements of specialist installations. These specialist installations were: ceilings and partitions, drainage, electrical installation and reticulation, humidification, air-conditioning and ventilation, landscaping, fire detection and protection, data and IT installation, telecoms, core drilling, access control, heat pumps, gas and gas conduits, roller shutter doors, piling and signage.

\section{Results}

Tables 2 and 3 show a summary of the portion of the construction cost components obtained from the cases examined.

Table 2: Construction Cost Distributed According to Constituent Resources for Renovation projects (Q1: 2016 Prices)

\begin{tabular}{|c|c|c|c|c|c|c|}
\hline \multirow{2}{*}{ Projects } & \multicolumn{6}{|c|}{ Resource Component Share (\%) } \\
\hline & Labour & Material & Plant & Preliminary & Subcontractor & Total \\
\hline R1. Admin building & 5.19 & 9.23 & 0.37 & 15.61 & 69.60 & 100 \\
\hline R2. Renovation of school building & 19.70 & 52.18 & 10.53 & 7.46 & 10.13 & 100 \\
\hline R3. Renovation of hospital & 28.82 & 12.95 & 2.76 & 14.01 & 41.47 & 100 \\
\hline $\begin{array}{l}\text { R4. Rehabilitation of municipal road } \\
\text { (concrete) }\end{array}$ & 7.08 & 54.26 & 16.90 & 21.75 & 0.00 & 100 \\
\hline $\begin{array}{l}\text { R5. Refurbishment of family and } \\
\text { regional Court }\end{array}$ & 34.30 & 42.87 & 5.19 & 3.87 & 13.76 & 100 \\
\hline R6. Renovation of community clinic & 13.89 & 31.00 & 3.01 & 7.44 & 44.66 & 100 \\
\hline Average share & 18.16 & 33.75 & 6.46 & 11.69 & 29.94 & 100 \\
\hline
\end{tabular}

Table 3: Construction Cost Distributed According to Constituent Resources for New projects (Q1: 2016 Prices)

\section{Projects}

Resource component share (\%)

\begin{tabular}{llllll}
\hline Labour & Material & Plant & Preliminary & Subcontractor & Total \\
\hline
\end{tabular}




\begin{tabular}{lcccccc}
\hline N1. New primary school & 23.83 & 49.81 & 3.77 & 6.24 & 16.35 & 100 \\
N2. New hospital & 8.89 & 24.98 & 1.14 & 10.16 & 54.86 & 100 \\
N3. New road (concrete) & 5.70 & 56.76 & 14.22 & 15.23 & 8.09 & 100 \\
N4. New admin building & 11.17 & 25.22 & 2.39 & 11.18 & 50.05 & 100 \\
N5. Waste management facility & 7.77 & 30.62 & 3.75 & 4.21 & 53.65 & 100 \\
N6. Community clinic (new) & 17.81 & 35.68 & 1.16 & 3.83 & 41.52 & 100 \\
\hline Average Share & $\mathbf{1 2 . 5 3}$ & $\mathbf{3 7 . 1 8}$ & $\mathbf{4 . 4 1}$ & $\mathbf{8 . 4 8}$ & $\mathbf{3 7 . 4 2}$ & $\mathbf{1 0 0}$ \\
\hline
\end{tabular}

Table 2 and 3 show that while the cost of materials had the highest proportion on the average $(33.75 \%)$ in large renovation projects, in newly built project, the value of specialist subcontractor work was the highest $(37.42 \%)$. The two resource components of building materials and specialist subcontractors account for a total of $63.69 \%$ and $74.6 \%$ of the total cost of renovation and new construction work respectively. It can be inferred from these findings that building material and sub-contracting are the most heavily weighted construction components in the cost of both new and renovation projects. The study therefore further explored the two components, building materials and sub-contracting, to determine the constituent elements of these resource factors.

The study sought to know the value of the key building materials used on the renovation and new building projects. Data related to this enquiry is presented in Figures 1 and 2, and Tables 4 and 5 .

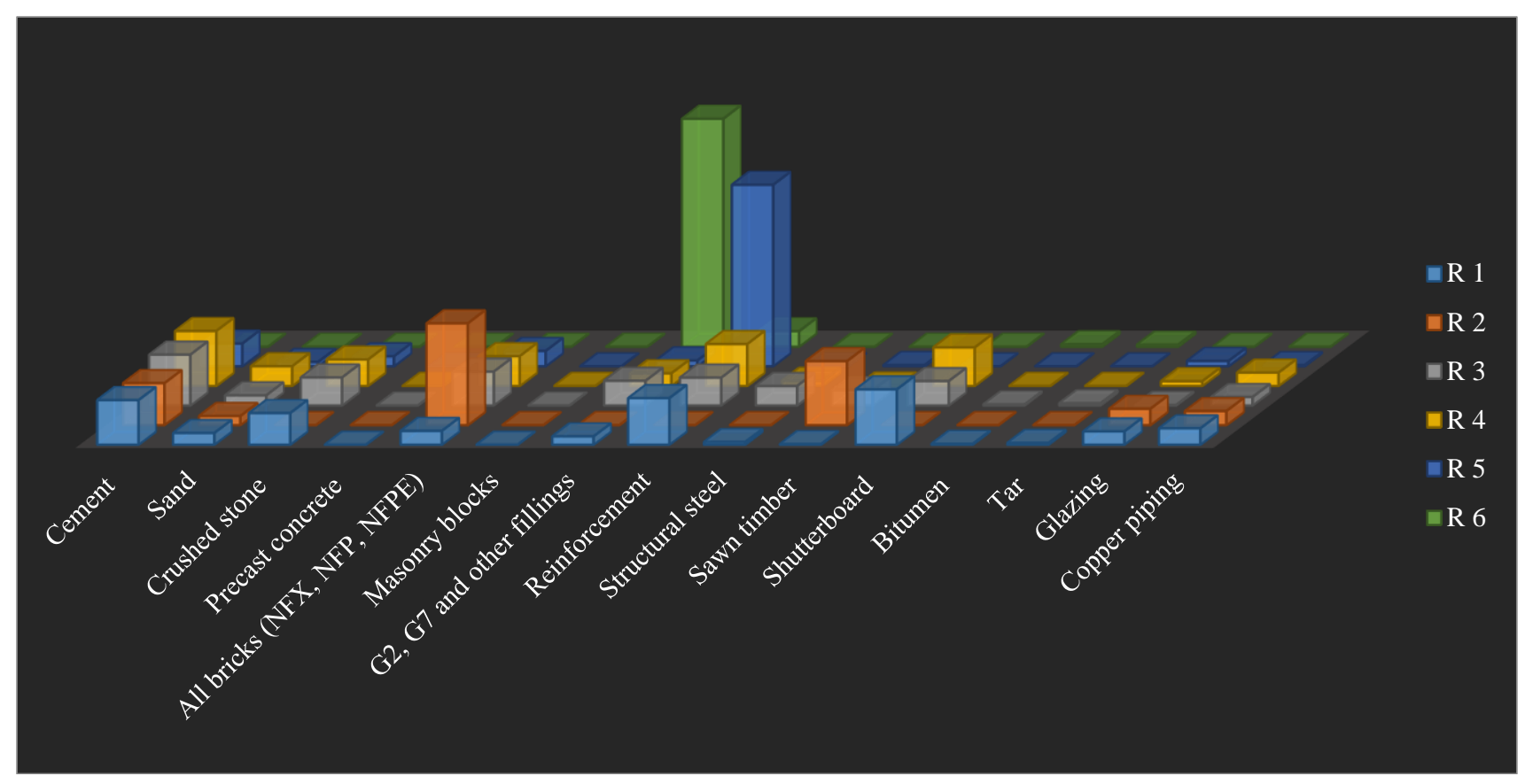

Figure 1: Value of Building Materials Used in Renovation Projects, Sorted by Type

Table 4: Distribution of the Value of Building Materials Used in Renovation Projects Sorted by Type

\begin{tabular}{lccccccc}
\hline \multicolumn{1}{c}{ Materials } & R 1 & R 2 & R 3 & R 4 & R 5 & $\begin{array}{c}\text { R 6 } \\
\text { utilization }\end{array}$ \\
\hline Reinforcement & $18.84 \%$ & $0.00 \%$ & $11.29 \%$ & $16.94 \%$ & $73.26 \%$ & $6.28 \%$ & $21.10 \%$ \\
G2, G7 and other fillings & $3.36 \%$ & $0.00 \%$ & $9.99 \%$ & $5.09 \%$ & $2.37 \%$ & $91.89 \%$ & $18.78 \%$ \\
Cement & $18.05 \%$ & $17.00 \%$ & $20.58 \%$ & $22.21 \%$ & $9.21 \%$ & $0.00 \%$ & $14.51 \%$ \\
All bricks (NFX, NFP, NFPE) & $5.59 \%$ & $41.18 \%$ & $13.70 \%$ & $12.03 \%$ & $6.21 \%$ & $0.00 \%$ & $13.12 \%$ \\
Shutterboard & $22.40 \%$ & $0.00 \%$ & $9.87 \%$ & $15.58 \%$ & $0.00 \%$ & $0.00 \%$ & $7.98 \%$ \\
Crushed stone & $12.78 \%$ & $0.00 \%$ & $11.35 \%$ & $10.68 \%$ & $4.04 \%$ & $0.00 \%$ & $6.47 \%$ \\
Sawn timber & $0.20 \%$ & $25.88 \%$ & $6.21 \%$ & $0.15 \%$ & $0.52 \%$ & $0.00 \%$ & $5.49 \%$ \\
Sand & $4.72 \%$ & $3.69 \%$ & $4.12 \%$ & $7.97 \%$ & $1.76 \%$ & $0.00 \%$ & $3.71 \%$ \\
Copper piping & $6.62 \%$ & $5.68 \%$ & $3.42 \%$ & $5.38 \%$ & $0.50 \%$ & $0.00 \%$ & $3.60 \%$ \\
Glazing & $5.37 \%$ & $6.58 \%$ & $0.25 \%$ & $1.90 \%$ & $2.14 \%$ & $0.00 \%$ & $2.71 \%$ \\
Structural steel & $1.06 \%$ & $0.00 \%$ & $7.89 \%$ & $2.06 \%$ & $0.00 \%$ & $0.00 \%$ & $1.83 \%$ \\
Tar & $0.68 \%$ & $0.00 \%$ & $0.91 \%$ & $0.00 \%$ & $0.00 \%$ & $0.84 \%$ & $0.41 \%$
\end{tabular}




\begin{tabular}{llllllll} 
Bitumen & $0.32 \%$ & $0.00 \%$ & $0.43 \%$ & $0.00 \%$ & $0.00 \%$ & $0.99 \%$ & $0.29 \%$ \\
Precast concrete & $0.00 \%$ & $0.00 \%$ & $0.00 \%$ & $0.00 \%$ & $0.00 \%$ & $0.00 \%$ & $0.00 \%$ \\
Masonry blocks & $0.00 \%$ & $0.00 \%$ & $0.00 \%$ & $0.00 \%$ & $0.00 \%$ & $0.00 \%$ & $0.00 \%$ \\
\hline
\end{tabular}

Table 4 and Figure 1 show that on the average and across the six renovation projects examined, reinforcement, filling, cement and bricks are used more, by value, while masonry blocks and precast concrete items are not used at all.

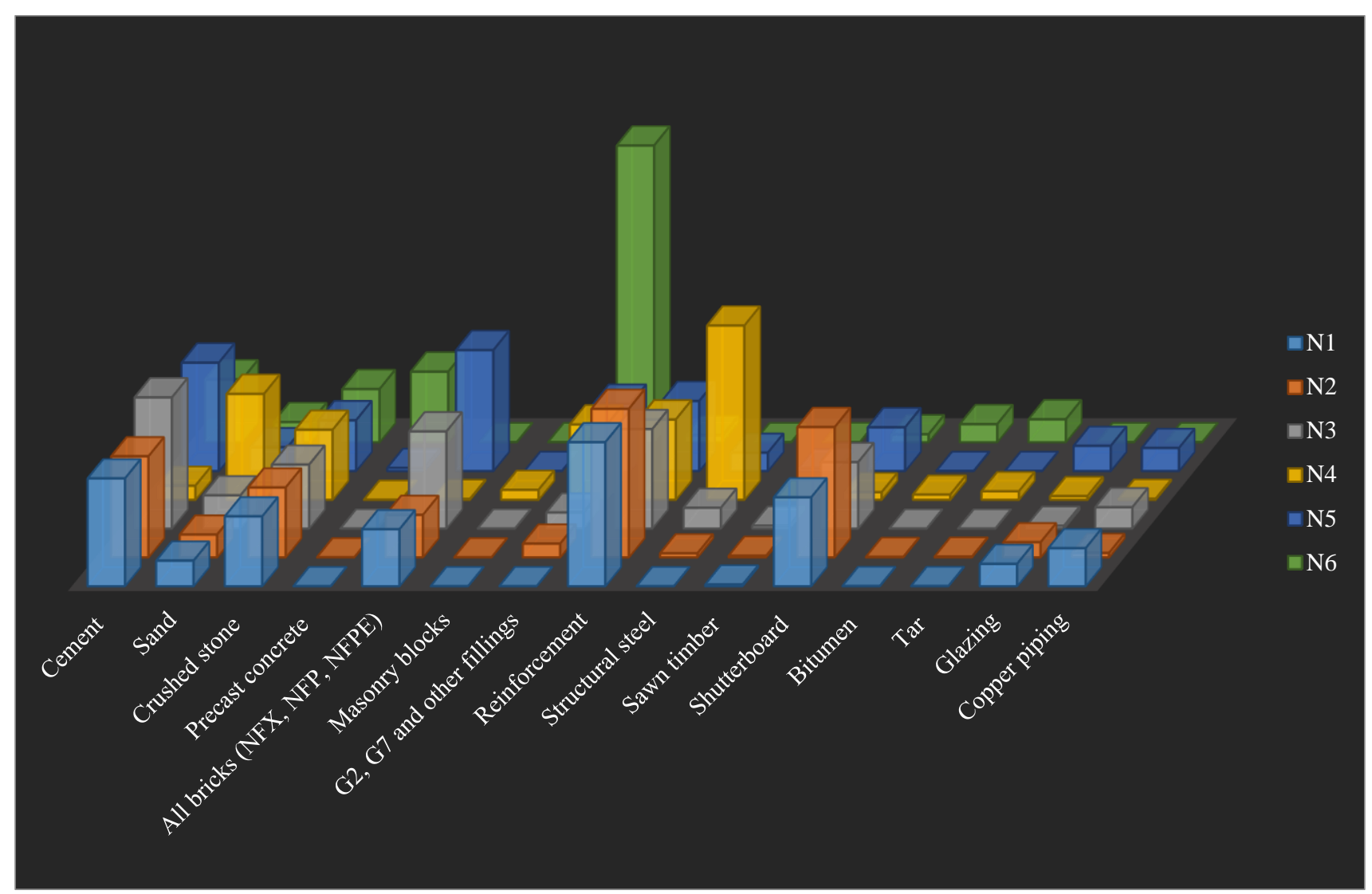

Figure 2: Value of Building Materials Used in New Projects, Sorted by Type

Table 5: Distribution of the Value of Building Materials Used in New Projects Sorted by Type

\begin{tabular}{lccccccc}
\hline \multicolumn{1}{c}{ Materials } & $\mathbf{N 1}$ & $\mathbf{N 2}$ & $\mathbf{N 3}$ & $\mathbf{N 4}$ & $\mathbf{N 5}$ & $\mathbf{N 6}$ & $\begin{array}{c}\text { Average } \\
\text { utilization }\end{array}$ \\
\hline Reinforcement & $25.96 \%$ & $26.74 \%$ & $17.93 \%$ & $14.45 \%$ & $12.57 \%$ & $1.22 \%$ & $16.48 \%$ \\
Cement & $19.42 \%$ & $18.22 \%$ & $23.60 \%$ & $2.53 \%$ & $19.41 \%$ & $11.26 \%$ & $15.74 \%$ \\
G2, G7 and other fillings & $0.00 \%$ & $2.48 \%$ & $2.88 \%$ & $13.57 \%$ & $12.06 \%$ & $53.01 \%$ & $14.00 \%$ \\
Crushed stone & $12.58 \%$ & $12.60 \%$ & $11.53 \%$ & $12.61 \%$ & $9.13 \%$ & $9.51 \%$ & $11.33 \%$ \\
Shutterboard & $16.01 \%$ & $23.49 \%$ & $11.97 \%$ & $1.35 \%$ & $7.87 \%$ & $1.43 \%$ & $10.35 \%$ \\
All bricks (NFX, NFP, NFPE) & $10.26 \%$ & $7.66 \%$ & $17.51 \%$ & $0.14 \%$ & $21.65 \%$ & $0.00 \%$ & $9.54 \%$ \\
Sand & $4.59 \%$ & $4.10 \%$ & $5.99 \%$ & $19.03 \%$ & $4.28 \%$ & $3.61 \%$ & $6.94 \%$ \\
Structural steel & $0.00 \%$ & $0.73 \%$ & $3.74 \%$ & $31.24 \%$ & $3.29 \%$ & $0.00 \%$ & $6.50 \%$ \\
Copper piping & $6.84 \%$ & $0.79 \%$ & $3.84 \%$ & $0.18 \%$ & $4.14 \%$ & $0.00 \%$ & $2.63 \%$ \\
Precast concrete & $0.00 \%$ & $0.00 \%$ & $0.00 \%$ & $0.00 \%$ & $0.55 \%$ & $12.62 \%$ & $2.20 \%$ \\
Glazing & $4.02 \%$ & $2.71 \%$ & $0.50 \%$ & $0.66 \%$ & $4.52 \%$ & $0.00 \%$ & $2.07 \%$ \\
Tar & $0.02 \%$ & $0.12 \%$ & $0.00 \%$ & $1.52 \%$ & $0.00 \%$ & $4.10 \%$ & $0.96 \%$ \\
Bitumen & $0.01 \%$ & $0.08 \%$ & $0.00 \%$ & $0.93 \%$ & $0.00 \%$ & $3.24 \%$ & $0.71 \%$ \\
Masonry blocks & $0.00 \%$ & $0.00 \%$ & $0.00 \%$ & $1.78 \%$ & $0.00 \%$ & $0.00 \%$ & $0.30 \%$ \\
Sawn timber & $0.28 \%$ & $0.28 \%$ & $0.51 \%$ & $0.00 \%$ & $0.52 \%$ & $0.00 \%$ & $0.27 \%$ \\
\hline
\end{tabular}


Table 5 and Figure 2 show that on the average and across the six new projects examined, reinforcement, cement, filling, crushed stone and shutterboards account for $67.9 \%$ of the building material component, while masonry blocks and sawn timber are used much less.
The study also sought to know the key specialist subcontractors by value that were engaged on the renovation and new building projects. Data related to this enquiry is presented in Figures 3 and 4, and Tables 6 and 7.

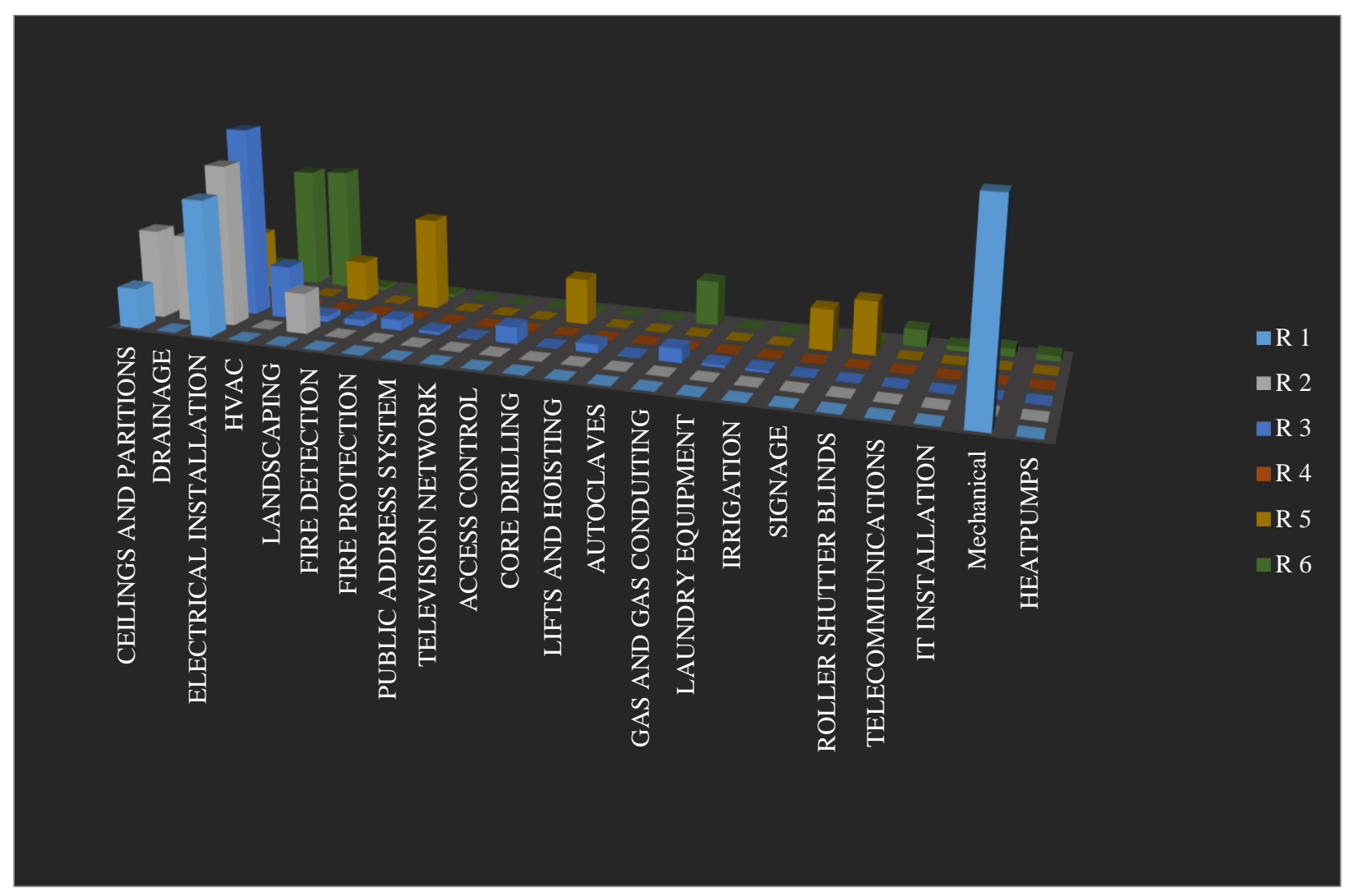

Figure 3: Value of Specialist Work in Renovation Projects, Sorted by Type

Table 6: Distribution of the value of Specialist Work Used in Renovation Projects Sorted by Type

\begin{tabular}{lccccccc}
\hline Specialist Subcontractor & $\mathbf{R} 1$ & $\mathbf{R} 2$ & $\mathbf{R ~ 3}$ & $\mathbf{R ~ 4}$ & $\mathbf{R ~ 5}$ & R 6 & $\begin{array}{l}\text { Average } \\
\text { utilization }\end{array}$ \\
\hline Electrical installation & $36.07 \%$ & $42.70 \%$ & $50.27 \%$ & 0 & $0.00 \%$ & $32.45 \%$ & $40.37 \%$ \\
Ceilings and partitions & $10.76 \%$ & $23.60 \%$ & $15.23 \%$ & 0 & $11.85 \%$ & $7.48 \%$ & $17.23 \%$ \\
Mechanical & $53.17 \%$ & $0.00 \%$ & $0.00 \%$ & 0 & $0.00 \%$ & $2.07 \%$ & $13.81 \%$ \\
HVAC & $0.00 \%$ & $0.00 \%$ & $14.01 \%$ & 0 & $0.00 \%$ & $33.12 \%$ & $11.78 \%$ \\
Drainage & $0.00 \%$ & $22.92 \%$ & $1.72 \%$ & 0 & $15.91 \%$ & $4.34 \%$ & $11.22 \%$ \\
Fire protection & $0.00 \%$ & $0.00 \%$ & $2.81 \%$ & 0 & $24.50 \%$ & $0.88 \%$ & $7.05 \%$ \\
Landscaping & $0.00 \%$ & $10.79 \%$ & $1.63 \%$ & 0 & $10.77 \%$ & $0.68 \%$ & $5.97 \%$ \\
Gas and gas conducting & $0.00 \%$ & $0.00 \%$ & $3.63 \%$ & 0 & $0.00 \%$ & $11.89 \%$ & $3.88 \%$ \\
Roller shutter blinds & $0.00 \%$ & $0.00 \%$ & $0.00 \%$ & 0 & $14.01 \%$ & $0.00 \%$ & $3.50 \%$ \\
Core drilling & $0.00 \%$ & $0.00 \%$ & $0.05 \%$ & 0 & $12.19 \%$ & $0.00 \%$ & $3.06 \%$ \\
Signage & $0.00 \%$ & $0.00 \%$ & $0.00 \%$ & 0 & $10.77 \%$ & $0.00 \%$ & $2.69 \%$ \\
Telecommunications & $0.00 \%$ & $0.00 \%$ & $0.00 \%$ & 0 & $0.00 \%$ & $4.48 \%$ & $1.12 \%$ \\
Access control & $0.00 \%$ & $0.00 \%$ & $4.35 \%$ & 0 & $0.00 \%$ & $0.00 \%$ & $1.09 \%$ \\
Lifts and hoisting & $0.00 \%$ & $0.00 \%$ & $2.28 \%$ & 0 & $0.00 \%$ & $0.00 \%$ & $0.57 \%$ \\
Fire detection & $0.00 \%$ & $0.00 \%$ & $1.63 \%$ & 0 & $0.00 \%$ & $0.00 \%$ & $0.41 \%$ \\
Heat pumps & $0.00 \%$ & $0.00 \%$ & $0.00 \%$ & 0 & $0.00 \%$ & $1.38 \%$ & $0.35 \%$ \\
It Installation & $0.00 \%$ & $0.00 \%$ & $0.00 \%$ & 0 & $0.00 \%$ & $1.22 \%$ & $0.31 \%$ \\
\hline
\end{tabular}




\begin{tabular}{llllllll}
\hline Public address system & $0.00 \%$ & $0.00 \%$ & $0.84 \%$ & 0 & $0.00 \%$ & $0.00 \%$ & $0.21 \%$ \\
Laundry equipment & $0.00 \%$ & $0.00 \%$ & $0.66 \%$ & 0 & $0.00 \%$ & $0.00 \%$ & $0.16 \%$ \\
Irrigation & $0.00 \%$ & $0.00 \%$ & $0.54 \%$ & 0 & $0.00 \%$ & $0.00 \%$ & $0.14 \%$ \\
Television network & $0.00 \%$ & $0.00 \%$ & $0.19 \%$ & 0 & $0.00 \%$ & $0.00 \%$ & $0.05 \%$ \\
Autoclaves & $0.00 \%$ & $0.00 \%$ & $0.15 \%$ & 0 & $0.00 \%$ & $0.00 \%$ & $0.04 \%$ \\
\hline
\end{tabular}

Table 6 and Figure 3 reveal that on the average and across the six renovation projects examined, the value of electrical installation, ceilings / partitions and mechanical
/ HVAC systems is higher, while the value of CCTV installation is much lower.

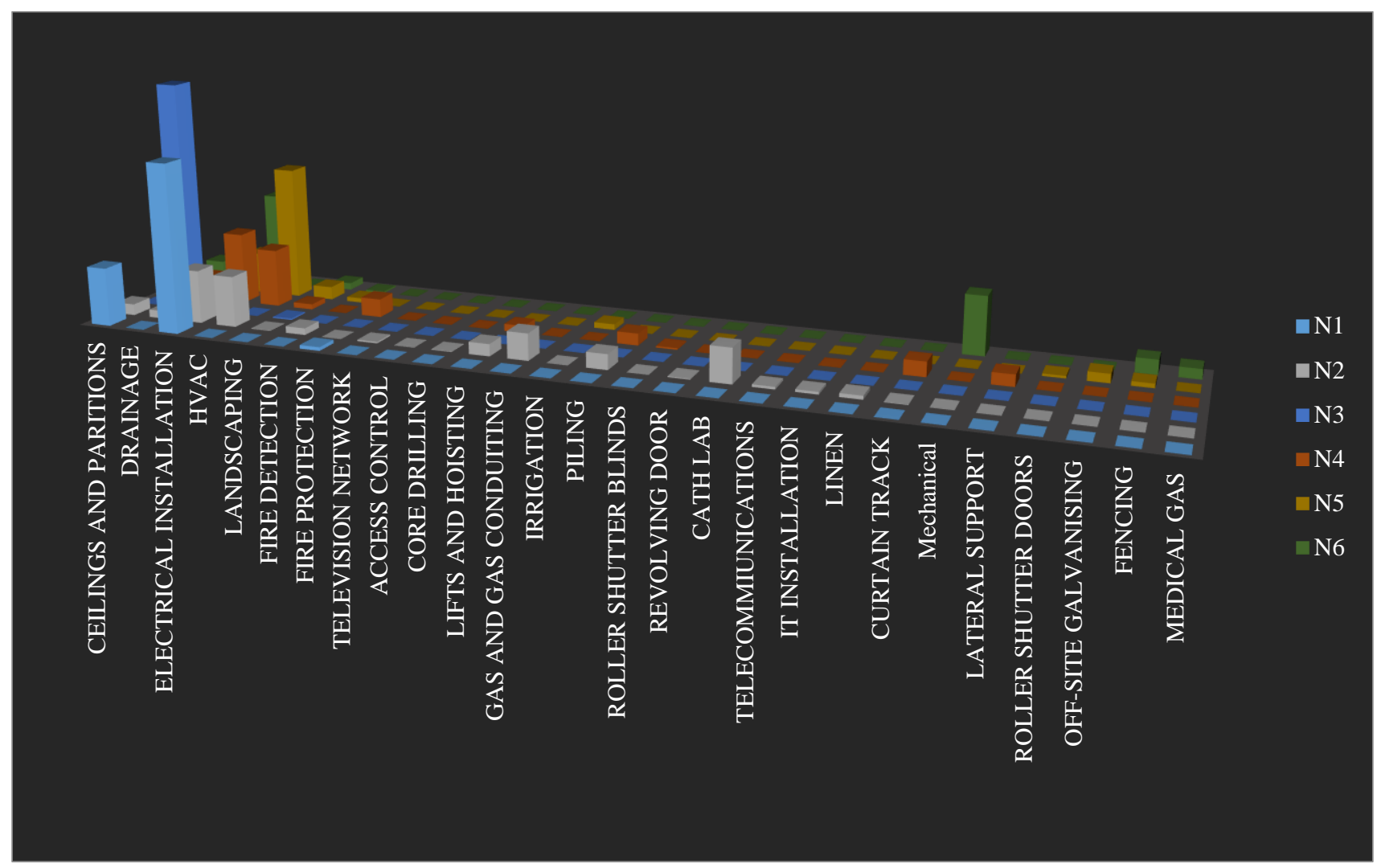

Figure 4: Value of Specialist Work in New Projects, Sorted by Type

Table 1: Distribution of the Value of Specialist Work Used in New Projects Sorted by Type

\begin{tabular}{lccccccc}
\hline Specialist subcontractor & $\mathbf{N 1}$ & $\mathbf{N 2}$ & $\mathbf{N 3}$ & $\mathbf{N 4}$ & $\mathbf{N 5}$ & $\mathbf{N 6}$ & $\begin{array}{c}\text { Average } \\
\text { utilization }\end{array}$ \\
\hline Electrical installation & $73.14 \%$ & $22.97 \%$ & $0.00 \%$ & $30.92 \%$ & $17.88 \%$ & $40.96 \%$ & $38.74 \%$ \\
Drainage & $0.00 \%$ & $3.35 \%$ & $99.47 \%$ & $9.95 \%$ & $6.40 \%$ & $12.12 \%$ & $30.34 \%$ \\
HVAC & $0.00 \%$ & $22.02 \%$ & $0.00 \%$ & $25.11 \%$ & $57.86 \%$ & $0.00 \%$ & $19.97 \%$ \\
Ceilings and partitions & $25.29 \%$ & $4.84 \%$ & $0.00 \%$ & $3.23 \%$ & $0.96 \%$ & $7.02 \%$ & $9.53 \%$ \\
Mechanical & $0.00 \%$ & $0.00 \%$ & $0.00 \%$ & $0.00 \%$ & $0.00 \%$ & $25.48 \%$ & $6.37 \%$ \\
Cath lab & $0.00 \%$ & $15.00 \%$ & $0.00 \%$ & $0.00 \%$ & $0.00 \%$ & $0.00 \%$ & $3.75 \%$ \\
Gas and gas conducting & $0.00 \%$ & $11.59 \%$ & $0.00 \%$ & $0.00 \%$ & $0.00 \%$ & $0.00 \%$ & $2.90 \%$ \\
Landscaping & $0.00 \%$ & $0.17 \%$ & $0.53 \%$ & $2.34 \%$ & $5.65 \%$ & $3.05 \%$ & $2.35 \%$ \\
Fencing & $0.00 \%$ & $0.00 \%$ & $0.00 \%$ & $0.00 \%$ & $1.88 \%$ & $6.31 \%$ & $2.05 \%$ \\
Piling & $0.00 \%$ & $6.66 \%$ & $0.00 \%$ & $5.17 \%$ & $0.00 \%$ & $0.00 \%$ & $1.66 \%$ \\
Fire detection & $0.00 \%$ & $2.90 \%$ & $0.00 \%$ & $0.00 \%$ & $1.94 \%$ & $0.68 \%$ & $1.38 \%$ \\
Lifts and hoisting & $0.00 \%$ & $5.25 \%$ & $0.00 \%$ & $3.07 \%$ & $0.00 \%$ & $0.00 \%$ & $1.31 \%$ \\
Medical gas & $0.00 \%$ & $0.00 \%$ & $0.00 \%$ & $0.00 \%$ & $0.00 \%$ & $4.39 \%$ & $1.10 \%$ \\
Off-site galvanizing & $0.00 \%$ & $0.00 \%$ & $0.00 \%$ & $0.00 \%$ & $3.89 \%$ & $0.00 \%$ & $0.97 \%$ \\
\hline
\end{tabular}




\begin{tabular}{llllllll}
\hline Irrigation & $0.00 \%$ & $0.00 \%$ & $0.00 \%$ & $0.00 \%$ & $2.47 \%$ & $0.00 \%$ & $0.62 \%$ \\
$\quad$ Linen & $0.00 \%$ & $1.59 \%$ & $0.00 \%$ & $0.00 \%$ & $0.00 \%$ & $0.00 \%$ & $0.40 \%$ \\
Fire protection & $1.57 \%$ & $0.00 \%$ & $0.00 \%$ & $7.93 \%$ & $0.00 \%$ & $0.00 \%$ & $0.39 \%$ \\
Telecommunications & $0.00 \%$ & $1.06 \%$ & $0.00 \%$ & $0.00 \%$ & $0.00 \%$ & $0.00 \%$ & $0.27 \%$ \\
It installation & $0.00 \%$ & $1.06 \%$ & $0.00 \%$ & $0.00 \%$ & $0.00 \%$ & $0.00 \%$ & $0.27 \%$ \\
Roller shutter doors & $0.00 \%$ & $0.00 \%$ & $0.00 \%$ & $0.00 \%$ & $1.06 \%$ & $0.00 \%$ & $0.26 \%$ \\
Television network & $0.00 \%$ & $0.64 \%$ & $0.00 \%$ & $0.00 \%$ & $0.00 \%$ & $0.00 \%$ & $0.16 \%$ \\
Revolving door & $0.00 \%$ & $0.36 \%$ & $0.00 \%$ & $0.00 \%$ & $0.00 \%$ & $0.00 \%$ & $0.09 \%$ \\
Core drilling & $0.00 \%$ & $0.21 \%$ & $0.00 \%$ & $0.00 \%$ & $0.00 \%$ & $0.00 \%$ & $0.05 \%$ \\
Curtain track & $0.00 \%$ & $0.21 \%$ & $0.00 \%$ & $6.46 \%$ & $0.00 \%$ & $0.00 \%$ & $0.05 \%$ \\
Access control & $0.00 \%$ & $0.07 \%$ & $0.00 \%$ & $0.00 \%$ & $0.00 \%$ & $0.00 \%$ & $0.02 \%$ \\
$\quad$ Roller shutter blinds & $0.00 \%$ & $0.03 \%$ & $0.00 \%$ & $0.72 \%$ & $0.00 \%$ & $0.00 \%$ & $0.01 \%$ \\
Lateral support & $0.00 \%$ & $0.00 \%$ & $0.00 \%$ & $5.10 \%$ & $0.00 \%$ & $0.00 \%$ & $0.00 \%$ \\
\hline
\end{tabular}

Table 7 and Figure 4 reveal that on the average and across the six new projects examined, electrical installation, drainage and HVAC systems account for a total of $89.05 \%$ of the total new building specialist subcontractor component, while the value of CCTV installation is much lower.

\section{Discussion of Findings}

The study examined the components of construction projects and whether there were construction resources that were the key project cost constituents. The study found that the building material and sub-contracting element were the key construction components contributing to the cost of both new and renovation projects. This finding is aligned with those of previous studies by Odediran and Windapo (2014), Skitmore, Runeson and Chang (2006), Lowe, Emsley, and Harding (2006).

The study also established that reinforcement is used most by value in both new and renovation projects, followed by cement, filling materials and crushed stones. The latter are used more by value in new projects, while filling materials of cement and bricks are used more by value in renovation projects. Furthermore, the electrical installation is installed most by value of total installation in both new and renovation projects and followed by celling and partition installations. The value of mechanical and HVAC installations is higher in renovation projects, while the drainage, HVAC and celling and partition installations is higher in new projects. This finding is of significance to policy makers and clients in the construction industry because it makes available the average cost of components and enables a consistent comparison of construction projects based on cost.

\section{Conclusions}

The study was able to identify the common components which contribute significantly to construction cost, in medium to large construction projects. The primary objective of any pricing regime should be to ensure that resources are allocated efficiently, and an understanding of the indicators and drivers of cost will aid decision making. This can enhance cost management related to the sector. Based on the analysis of the data collected, it can be inferred that the resource factors with a significant share of construction cost in South Africa, are specialist subcontractors, and materials, while labour cost is observed to be close to the BRICs average cost in absolute terms.

The results imply that challenges such as the weak Rand relative to the US dollar will continue to exert pressure on construction cost, through the material cost component. This is because the import of vital equipment and materials will raise cost above specified budget, thereby increasing the overall cost of the project. However, this may be due to the fact that many of the construction components, including materials, labour and equipment are obtained in South Africa. Therefore, the effects of import costs in the construction industry are not felt to the same extent in other industries.

The data shows that materials and sub-contracted work are the significant cost drivers responsible for trends in the cost of construction projects in South Africa, and that the future levels of the cost of construction work can be predicted using known levels of material and specialist subcontractors' costs. Another significant finding is about the use of specialist subcontractors as a resource on both new and renovation projects. It can be inferred from the results obtained that there are benefits to the use of specialist subcontractors in construction project delivery. This is because the subcontractor has knowledge which can be highly utilized across various project types. As a result of this, the specialist subcontractors can examine cost projections in different and favourable ways, not normally used by the main contractor. The subcontractors' knowledge may make for better coordination and planning and may lower overall costs on projects.

Furthermore, it is expected that in the long term, changes in the price of materials will also be a big factor in increasing future costs of construction. For example, it is expected that building materials affected by international trade, such as cement, reinforcement and bitumen, which have abnormal price growth, will affect future levels of construction costs.

\section{Recommendations}


To ensure an effective cost driving mechanism, in addition to designing an appropriate pricing policy to minimize production cost, it is important that sound investment decisions and improved management oversight are implemented to ensure that the cost of labour, plant, fuel and material inputs to production are minimised, thereby streamlining operations. Also, a database for the construction sector in South Africa should be properly developed, to facilitate proper estimation of construction cost, as well as improvement in risk management. However, there are at least two constructing firms that provide contractors with cost data, not in the form of indices, but in Rands and cents. These consulting firms have seen the gap in the market because neither the government, nor the professions, are willing to finance a national cost database such as the Building Cost Information Service (BCIS) in London.

The South African government, using the management oriented procurement method, should develop a system that can be used to increase the participation of specialist subcontractors in the construction project delivery process. Materials are also a

\section{References}

Akintoye, A. (2000). Analysis of Factors Influencing Project Cost Estimating Practice. Construction Management and Economics, 18(1), 77-89.

Ashuri, B., \& Lu, J. (2010). Time Series Analysis of ENR Construction Cost Index. Journal of Construction Engineering and Management, 136(11), 1227-1237.

Bureau of Economic Research. (2016). BER/MFA Building Costs Information Service Report - First Quarter 2016. Stellenbosch: Bureau of Economic Research/Medium-Term Forecasting Associates.

Chappel, D., Cowlin, M., \& Dunn, D. (2010). Building Law Encyclopaedia. West Sussex, United Kingdom: Wiley-Blackwell.

Compass International Consultants Inc. (2016). Global Construction Costs 2016. Morrisville, Pennsylvania: Compass International Consultants Inc.

Eastham, R. (1986). Contractors' Perceptions of Factors Influencing Tender Prices for Construction Works. MSc Thesis, University of Salford, Department of Surveying.

Lowe, D., Emsley, M., \& Harding, A. (2006). Predicting Construction Cost Using Multiple Regression Techniques. Journal of Construction Engineering and Management, 132(7), 750-758. big cost that needs to be managed effectively by all stakeholders, to ensure that materials are used efficiently on site, so as to reduce waste. It is also important that a Building Industry Price Book be instituted by the cidb/DPW to track the trends in building components and material prices. The results of the study provide significant information for planners, estimators, project and construction managers. These data are useful for resource planning and management of construction projects.

Further studies should seek to determine conclusively whether the cost of cement, reinforcement, timber, bitumen and bricks is related to future levels of construction costs in South Africa.

\section{Acknowledgement}

This work is based on research supported by the cidb and DPW of South Africa. The opinions, findings, conclusions and recommendations expressed in the research are those of the authors and should not be attributed to the cidb or DPW.

Ng, S., Cheung, S., Skitmore, R., Lam, K., \& Wong, L. (2000). Prediction of Tender Price Index Directional Changes. Construction Management and Economics, 18(1).

Odediran, S., \& Windapo, A. (2014). Systematic Review of Factors Influencing the Cost of Performance in Building Projects. In S. Laryea, \& E. Ibem (Ed.), 8th Construction Industry Development Board (cidb) Postgraduate Conference, 10-11 February, (pp. 501-520). Johannesburg.

Olatunji, O. (2010). The impact of Oil Price Regimes on Construction Cost in Nigeria. Construction Management and Economics, 28(1), 747-759.

Sawhney, A., Walsh, K., \& Brown IV, A. (2004). International Comparison of Cost for the Construction Sector: towards a Conceptual Model. Civil Engineering and Environmental Systems, 21(3), 151-167.

Skitmore, M., Runeson, G., \& Chang, X. (2006). Construction Price Formation: Full-cost pricing or Neoclassical Microeconomic Theory? Construction Management and Economics, 24(7), 773-783.

Snyman, G. (n.d). Using Knowledge of the Business Cycle to Forecast Building Costs. Stellenbosch: Building Eonomists. 